\title{
ANALISIS DAYA SAING EKSPOR BIJI KAKAO INDONESIA KE MALAYSIA
}

\author{
Doni Sahat Tua Manalu \\ Dosen Politeknik Agroindustri \\ Email : manaludoni@gmail.com
}

\begin{abstract}
ABSTRAK
Indonesia merupakan penghasil kakao terbesar ketiga di dunia. Sebagian besar kakao dijual dengan ekspor. Maka pemerintah menerapkan peraturan yang membatasi ekspor kakao. Menurunnya ekspor kakao mengakibatkan turunnya produksi kakao. Maka diperlukan analisis tentang daya saing perdagangan kakao. Tujuan tulisan ini adalah menganalisis daya saing ekspor biji kakao (kode HS 18010) Indonesia ke pasar Malaysia serta menganalisis kebijakan perdagangan kakao Indonesia. Metode penelitian yang dilakukan menggunakan data sekunder dengan jenis data yang digunakan dalam penelitian ini adalah kuantitatif dan diperoleh dari Direktorat Jenderal Perkebunan, Badan Pusat Statistik, International Trade Statistics Database (UN Comtrade) serta penelitian-penelitian terdahulu yang dianalisis dengan menggunakan Revealed Comparative Advantage (RCA). Hasil penelitian dapat disimpulkan bahwa nilai rata-rata RCA biji kakao Indonesia ke Malaysia dari tahun 1991 - 2017 adalah sebesar 22, artinya Indonesia memiliki keunggulan komparatif yang relaitf tinggi. Namun, pada periode 2011 - 2017, nilai RCA cenderung menurun karena tidak banyaknya pengolahan kakao di Indonesia sehingga komoditas yang di ekspor hanya mengandalkan hasil primer berupa biji kakao. Nilai ekspor biji kakao sebagai bahan mentah menjadi faktor yang memengaruhi nilai ekspor yang rendah karena produk tidak diolah sehingga tidak memiliki nilai yang lebih tinggi. Daya saing ekspor biji kakao Indonesia di pasar internasional dengan negara tujuan Malaysia secara keseluruhan masih memiliki keunggulan komparatif karena biayanya yang rendah dibandingkan negara lain sehingga Indonesia mampu bersaing.
\end{abstract}

Kata kunci : Biji Kakao, Daya Saing, Ekspor

\begin{abstract}
Indonesia is the third largest cocoa producer in the world. Most of the cacao is traded by export. The government implements regulations that restrict the export of cocoa. The
\end{abstract}


decline in cocoa exports causes a decline in cocoa production. It would require an analysis of competitiveness of processed cocoa on the world market. Then we need an analysis of the competitiveness of the cocoa trade. The purpose of this paper is to analyze the competitiveness of Indonesia's cocoa bean exports (HS code 18010) to the Malaysian market and to analyze Indonesia's cocoa trade policy. The research method was used by secondary data with the type of data used in this study was quantitative and was obtained from the Directorate General of Plantations, the Central Statistics Agency, the International Trade Statistics Database (UN Comtrade) and research studies which examined using Revealed Comparative Advantage (RCA). The results of the study can be concluded from the average RCA value of Indonesian cocoa beans to Malaysia from 1991 2017 totaling 22, that means Indonesia has a comparatively high comparative advantage. However, in the period of 2011 -2017, the RCA value tends to decrease because it does not many processing cocoa in Indonesia so that it only increases the primary yield containing cocoa beans. The export value of cocoa beans as raw material can be a factos that increase the low export value because the product cannot be processed properly, so it does not have a higher value. The competitiveness of Indonesia's cocoa exports in the international market with the destination country of Malaysia has a comparative total because of its low cost compared to other countries so that Indonesia is able to compete.

Keywords: Cocoa, Competitiveness, Export

\section{PENDAHULUAN}

Indonesia adalah negara agraris yang mayoritas penduduknya bermata pencaharian di bidang pertanian. Oleh karena itu, sektor pertanian memegang peranan penting dalam pembangunan negara. Pertanian sendiri dalam arti luas meliputi pertanian, perkebunan, peternakan, perikanan, dan kehutanan. Salah satu komoditas unggulan ekspor Indonesia adalah Kakao dan yang memiliki peran dalam pembangunan Indonesia khususnya pada subsektor perkebunan. Hal tersebut dapat dilihat pada Tabel 1. Berdasarkan laju pertumbuhan PDB Indonesia atas dasar harga konstan 5 tahun terakhir, sektor perkebunan menjadi sektor yang paling besar kontribusinya dalam pertumbuhan PDB dan terus mengalami peningkatan setiap tahunnya.

Tabel 1. Laju pertumbuhan PDB Indonesia atas dasar harga konstan tahun 2012 - 2016

\begin{tabular}{lrrrrr}
\hline \multicolumn{1}{c}{ Sektor } & \multicolumn{1}{c}{$\mathbf{2 0 1 2}$} & $\mathbf{2 0 1 3}$ & $\mathbf{2 0 1 4}$ & \multicolumn{1}{c}{$\mathbf{2 0 1 5}$} & \multicolumn{1}{c}{$\mathbf{2 0 1 6}$} \\
\hline Tanaman Pangan & $263.076,2$ & $268.268,2$ & $268.426,9$ & $280.018,8$ & $287.100,7$ \\
Perkebunan & $301.019,5$ & $319.532,6$ & $338.502,2$ & $345.164,9$ & $357.234,8$ \\
Peternakan & $119.249,8$ & $125.302,3$ & $132.221,1$ & $136.936,4$ & $142.459,6$ \\
Perikanan & $164.264,3$ & $176.149,3$ & $189.089,7$ & $204.016,8$ & $214.523,2$ \\
Kehutanan & $58.872,0$ & $59.228,8$ & $59.573,5$ & $60.757,4$ & $59.708,9$ \\
\hline
\end{tabular}

Sumber : Direktorat Jenderal Peternakan dan Kesehatan Hewan, 2017 
Selain untuk memenuhi kebutuhan dalam negeri serta membantu laju pertumbuhan domestik, subsektor perkebunan juga berperan penting dalam pasar internasional melalui kegiatan ekspor dan impor. Menurut Badan Pusat Statistik, produksi kebun atau lazim disebut produksi primer adalah produksi atau hasil yang di panen dari usaha perkebunannya tanpa melalui proses pengolahan lebih lanjut. Contoh produksi kebun atau produksi primer : Perkebunan karet produksi primernya adalah Latex, Lumb, Perkebunan kelapa sawit produksi primernya adalah Tandan Buah Segar, Perkebunan kakao produksi primernya adalah Buah Basah.

Kakao adalah salah satu komoditas ekspor dari subsektor perkebunan yang merupakan komoditas unggulan nasional yang memberikan sumbangan devisa ketiga terbesar setelah kelapa sawit dan karet (Goenadi et al, 2007). Selain itu, luas areal serta produktivitas total kakao pada tahun 2016 silam mengalami peningkatan dari tahun sebelumnya. Luas areal kakao mencapai 1.722 .315 ha dengan produktivitas sebesar 760.429 ton (Direktorat Jenderal Perkebunan, 2016). Hal ini menunjukkan bahwa kakao merupakan komoditas yang sangat penting dalam perekonomian Indonesia.

Dalam perdagangan internasional, biji kakao Indonesia merupakan salah satu produk unggulan yang di ekspor ke negara-negara lain. Menurut data statistik perkebunan Indonesia komoditas kakao tahun 2014, negara-negara lain seperti Malaysia, Singapura, India, Thailand, dan China menjadi negara importir terbesar komoditas biji kakao Indonesia.

Tabel 2. Volume dan Nilai Ekspor - Impor Kakao Biji Menurut Negara Tujuan dan Asal Tahun 2014

\begin{tabular}{lrr}
\hline \multicolumn{1}{c}{ Negara Tujuan } & Volume Ekspor $\mathbf{( k g )}$ & Nilai Ekspor (US\$) \\
\hline Malaysia & 38.933 .042 & 119.161 .698 \\
Singapura & 9.970 .176 & 31.133 .557 \\
India & 7.790 .101 & 23.191 .379 \\
Thailand & 4.978 .471 & 16.177 .625 \\
China & 480.005 & 1.285 .155 \\
\hline
\end{tabular}

Sumber: Statistik Perkebunan Indonesia Komoditas Kakao, 2014

Adanya data di atas menunjukkan tren ekspor biji kakao Indonesia dengan kode HS 18010 masih berpotensi besar yang ditunjukkan dalam peningkatan luas areal dan produktivitas serta ekspor biji kakao Indonesia, khususnya pada negara tujuan Malaysia sebagai negara importir terbesar. Untuk itu, ekspor biji kakao Indonesia harus memiliki daya saing dalam bentuk keunggulan komparatif dan kompetitif agar tetap mampu bersaing bahkan menjadi pemimpin di pasar internasional. Penelitian dilakukan untuk menganalisis daya saing perdagangan biji kakao Indonesia di pasar internasional dengan negara tujuan Malaysia. 
Berdasarkan uraian sebelumnya maka tujuan tulisan ini adalah menganalisis daya saing ekspor biji kakao (kode HS 18010) Indonesia ke pasar Malaysia serta menganalisis kebijakan perdagangan kakao Indonesia.

\section{METODOLOGI PENELITIAN}

\section{Jenis dan Sumber Data}

Jenis data yang digunakan dalam penelitian ini adalah kuantitatif dengan sumber data sekunder. Data diperoleh dari Direktorat Jenderal Perkebunan, Badan Pusat Statistik, International Trade Statistics Database (UN Comtrade), dan penelitian-penelitian terdahulu.

\section{Analisis Data}

Analisis daya saing dilakukan dengan menggunakan pendekatan matematis terhadap ukuran daya saing komoditas di pasar internasional. Ukuranukuran daya saing yang digunakan adalah Revealed Comparative Advantage (RCA). RCA merupakan salah satu metode yang dapat digunakan untuk mengukur keunggulan komparatif komoditas suatu negara di pasar dunia. Dalam analisis ini akan dihitung RCA dari negara-negara eksportir biji kakao di seluruh dunia ke negara tujuan Malaysia, sehingga keunggulan komparatifnya dapat dibandingkan. Secara matematis RCA dirumuskan sebagai berikut :

$$
R C A_{i j t}=\frac{X_{i j t} / X_{j t}}{W_{i t} / W_{t}}
$$

Dimana:

Xijt : Nilai ekspor komoditi i oleh negara j pada tahun $t$

Xjt : Nilai ekspor negara $\mathrm{j}$ pada tahun $\mathrm{t}$

Wit : Nilai ekspor dunia komoditas i pada tahun $t$

Wt : Nilai ekspor dunia pada tahun $t$

\section{HASIL DAN PEMBAHASAN}

\section{Analisis Daya Saing Ekspor Biji Kakao Indonesia ke Malaysia}

Keunggulan komparatif perdagangan kakao Indonesia baik dalam bentuk biji maupun produk olahan diukur dengan Revealed Comparative Advantage (RCA). Dalam analisis ini, akan dibandingkan nilai RCA biji kakao (kode HS 18010) Indonesia dengan negara-negara lainnya di pasar dunia ke negara tujuan Malaysia. Semakin tinggi nilai RCA, maka negara tersebut memiliki keunggulan 
komparatif yang lebih tinggi. Sedangkan jika nilai RCA lebih kecil dari 1, maka negara tersebut tidak memiliki keunggulan komparatif.

Tabel 3. Nilai RCA Biji Kakao Indonesia ke Malaysia Tahun 1991 - 2017

\begin{tabular}{|c|c|c|c|c|c|}
\hline Tahun & $\begin{array}{c}\text { Nilai } \\
\text { Ekspor } \\
\text { Kakao Ina } \\
\text { Ke } \\
\text { Malaysia } \\
\end{array}$ & $\begin{array}{c}\text { Nilai Ekspor } \\
\text { Total Ina Ke } \\
\text { Malaysia }\end{array}$ & $\begin{array}{c}\text { Nilai Ekspor } \\
\text { Kakao Dunia Ke } \\
\text { Malaysia }\end{array}$ & $\begin{array}{c}\text { Nilai Total Ekspor } \\
\text { Dunia Ke } \\
\text { Malaysia }\end{array}$ & $\begin{array}{l}\text { RCA Kakao } \\
\text { Ina Ke } \\
\text { Mlysia }\end{array}$ \\
\hline 1991 & 582,174 & $341,759,424$ & 821,253 & $36,581,322,168$ & 76 \\
\hline 1992 & $1,411,608$ & $487,518,176$ & $1,611,437$ & $39,788,383,435$ & 71 \\
\hline 1993 & $1,193,489$ & $585,962,816$ & $2,664,338$ & $45,389,967,912$ & 35 \\
\hline 1994 & $2,946,787$ & $738,465,024$ & $11,917,417$ & $59,085,992,781$ & 20 \\
\hline 1995 & $12,381,884$ & $986,545,344$ & $39,844,346$ & $77,045,596,053$ & 24 \\
\hline 1996 & $2,135,810$ & $1,109,703,040$ & $24,885,189$ & $77,904,686,076$ & 6 \\
\hline 1997 & $14,315,285$ & $1,357,208,576$ & $40,607,695$ & $78,433,583,104$ & 20 \\
\hline 1998 & $37,948,588$ & $1,358,452,608$ & $67,806,307$ & $57,759,420,674$ & 24 \\
\hline 1999 & $26,852,647$ & $1,335,907,858$ & $42,082,657$ & $64,939,219,363$ & 31 \\
\hline 2000 & $44,255,658$ & $1,971,841,741$ & $68,129,068$ & $81,957,250,044$ & 27 \\
\hline 2001 & $73,542,581$ & $1,778,626,157$ & $82,625,628$ & $73,846,608,845$ & 37 \\
\hline 2002 & $112,309,052$ & $2,029,947,368$ & $120,307,032$ & $86,136,022,725$ & 40 \\
\hline 2003 & $206,194,994$ & $2,363,850,125$ & $238,044,515$ & $83,613,981,628$ & 31 \\
\hline 2004 & $167,100,927$ & $3,016,047,968$ & $232,897,933$ & $105,156,808,107$ & 25 \\
\hline 2005 & $193,706,892$ & $3,431,299,664$ & $281,642,750$ & $114,289,820,494$ & 23 \\
\hline 2006 & $234,811,717$ & $4,110,757,004$ & $379,937,477$ & $131,127,047,764$ & 20 \\
\hline 2007 & $296,882,018$ & $5,096,063,502$ & $493,131,524$ & $146,104,307,073$ & 17 \\
\hline 2008 & $468,788,272$ & $6,432,551,930$ & $662,583,161$ & $155,660,819,369$ & 17 \\
\hline 2009 & $451,582,509$ & $6,811,823,548$ & $603,974,717$ & $123,575,279,300$ & 14 \\
\hline 2010 & $550,917,224$ & $9,362,332,453$ & $718,042,243$ & $164,586,273,423$ & 13 \\
\hline 2011 & $411,106,422$ & $10,995,846,600$ & $889,978,594$ & $187,573,009,395$ & 8 \\
\hline 2012 & $225,747,755$ & $11,280,284,955$ & $739,503,301$ & $196,196,618,679$ & 5 \\
\hline 2013 & $302,161,629$ & $10,666,609,471$ & $726,097,506$ & $205,813,524,818$ & 8 \\
\hline 2014 & $119,161,698$ & $9,731,540,673$ & $521,111,189$ & $208,823,428,627$ & 5 \\
\hline 2015 & $77,445,371$ & $7,630,889,322$ & $423,057,816$ & $176,174,598,214$ & 4 \\
\hline 2016 & $56,605,227$ & $7,112,008,233$ & $522,803,533$ & $168,375,228,233$ & 3 \\
\hline 2017 & $48,609,907$ & $8,467,527,299$ & $574,302,831$ & $193,855,940,671$ & 2 \\
\hline \multicolumn{5}{|c|}{ Rata-Rata RCA } & 22 \\
\hline
\end{tabular}

Sumber: Un Comtrade (Diolah)

Sebagai negara eksportir biji kakao terbesar ketiga di dunia, Indonesia memiliki keunggulan komparatif yang relatif tinggi untuk negara tujuan Malaysia. Pada periode 1991 - 2017, nilai RCA rata-rata biji kakao Indonesia adalah sebesar 22 (Tabel 3). Namun, pada tahun 2011 - 2017 cenderung terjadi penurunan RCA dibanding tahun-tahun sebelumnya karena peningkatan nilai 
ekspor biji kakao Indonesia relatif lebih lambat dibandingkan dengan peningkatan nilai ekspor biji kakao dunia.

Penurunan RCA biji kakao Indonesia ke Malaysia terjadi karena daya saing ekspor biji kakao Indonesia di pasar internasional telah memasuki tahap kematangan. Minimnya pengolahan kakao di Indonesia menyebabkan adanya kesempatan bagi negara lain untuk memanfaatkan hal tersebut sehingga negara tersebut memiliki keunggulan komparatif yang lebih baik. Sebagai contoh pada penelitian yang dilakukan oleh Lubis dan Nuryanti (2011), negara Malaysia telah menghentikan ekspor biji kakao ke China dan menggeser ke produk setengah jadi. Indonesia tidak meraih keuntungan dalam perdagangan bebas jika hanya dengan mengekspor produk primer seperti biji kakao. Oleh sebab itu, perlu dilakukan penataan ulang industri kakao nasional, dengan tujuan mengekspor produk kakao olahan bernilai tambah tinggi. Kebijakan lebih lanjut adalah mendorong dibangunnya industri kakao untuk menghasilkan lemak dan pasta kakao.

Namun begitu, berdasarkan nilai RCA biji kakao Indonesia ke Malaysia masih menunjukkan bahwa Indonesia memiliki keunggulan komperatif dengan nilai yang melebihi angka 1 . Indonesia mampu bersaing di pasar dunia karena memiliki keunggulan komparatif dan terspesialisasi pada produk kakao, yang artinya Indonesia bisa memproduksi kakao dengan biaya yang lebih murah dibandingkan dengan negara lain. Hal tersebut yang menjadi daya tarik kakao Indonesia pada pasar internasional dimana negara-negara pengimpor bisa mendapatkan kebutuhannya dengan harga rendah. Hasil penelitian ini sejalan dengan penelitian (Suryana, Fariyanti dan Rifin, 2015) bahwa ekspor kakao Indonesia dalam bentuk biji memiliki daya saing tertinggi dibandingkan kakao dalam bentuk olahan.

\section{Kebijakan Perdagangan Internasional Ekspor Biji Kakao Indonesia}

Pada perekonomian suatu negara, kebijakan perdagangan internasional memiliki peran yang sangat penting. Kebijakan perdagangan tersebut pada umumnya diutamakan untuk perluasan pasar internasional dan proteksi bagi pembeli domestik (industri atau rumah tangga). Namun tidak tertutup kemungkinan, kebijakan perdagangan tersebut ditujukan untuk meningkatkan penerimaan pemerintah melalui pajak atau pungutan dan terkait dengan kebijakan luar negeri suatu negara atau alasan-alasan politik. Kakao merupakan salah satu komoditi ekspor terbesar Indonesia sehingga komoditi kakao sering mendapat perhatian khusus dari pemerintah. Berikut adalah beberapa kebijakan perdagangan internasional untuk komoditas kakao Indonesia yang berlaku :

\section{Subsidi Pemerintah}

Faktor-faktor yang secara potensial memengaruhi ekspor kakao Indonesia adalah harga ekspor kakao Indonesia, pertumbuhan produksi kakao, nilai tukar rupiah dan trend waktu. Sementara rencana kebijakan pemberian subsidi harga 
pupuk berdampak positif meningkatkan produksi dan ekspor kakao Indonesia. Implikasinya adalah bahwa kebijakan subsidi harga pupuk masih dapat diharapkan sebagai strategi kunci untuk memacu produksi dan ekspor kakao Indonesia. Dengan adanya dukungan subsidi dari pemerintah, petani kakao dapat meningkatkan kualitas serta produktivitas hasil panennya karena penggunaan bibit unggul, pupuk organik, dll (Arsyad, Sinaga, dan Yusuf, 2011).

\section{Pajak Pertambahan Nilai 10 Persen (PPN)}

Pemerintah pernah menetapkan Pajak Pertambahan Nilai (PPN) 10 persen untuk komoditi pengolahan kakao di dalam negeri. Kebijakan pajak ekspor kakao mengandung konsekuensi yang menguntungkan dan merugikan. Namun kebijakan tersebut dinilai kurang efektif. Disini yang paling dirugikan adalah petani kakao. Dampak dari PE kakao menguntungkan industri pengolahan kakao, pemerintah dan pesaing ekspor Indonesia untuk produk-produk tersebut. Industri pengolahan kakao diuntungkan karena penerapan PE akan menekan harga kakao dan produk olahannya di pasar dalam negeri. Dari sisi lain, kebijakan PE kakao menimbulkan kerugian pihak produsen kakao (eksportir). Bagi eksportir kakao kerugiannya dapat ditrasmisikan kepada petani. Sementara di pihak petani kakao, kerugian ditanggungnya sendiri sehingga kerugian terbesar berada diposisinya (Elfiana, 2014).

\section{Bea Keluar}

Kebijakan pajak ekspor biji kakao bertujuan untuk menghambat ekspor biji kakao dan untuk meningkatkan pasokan biji kakao industri dalam negeri. Data menunjukkan bahwa setelah pemberlakuan bea keluar, ekspor biji kakao mengalami penurunan dan jumlah perusahaan pengolahan kakao mengalami peningkatan. Namun demikian, industri pengolahan kakao belum beroperasi dalam kapasitas penuh. Rendahnya kualitas biji kakao yang diproduksi di Indonesia merupakan faktor utamanya. Untuk itu direkomendasikan agar pendapatan pemerintah dari bea keluar ekspor biji kakao dimanfaatkan kembali untuk pembinaan petani dalam meningkatkan kualitas biji kakao (Syadullah, 2012).

\section{Penetapan Harga Patokan Ekspor}

Salah satu contoh kasus kebijakan penetapan harga patokan ekspor adalah kebijakan pemerintah Indonesia menetapkan harga patokan ekspor produk kakao karena adanya proteksi perdagangan yang diterapkan oleh Pemerintah Tiongkok. Seiring terjadinya perdagangan bebas antara negara-negara ASEAN dengan Cina termasuk Indonesia, maka dalam perjalanannya pemerintah Cina telah melakukan diskriminasi terhadap kakao (cocoa cake) asal Indonesia dengan cara mengenakan tarif Bea Masuk (BM) sebesar 10 persen ke Cina, sedangkan impor kakao dari Malaysia tidak dikenakan bea masuk atau 0 persen. Perlakuan 
diskriminatif tersebut sangat merugikan ekspor kakao Indonesia ke pasar Cina. Hal ini ditambah lagi dengan Cina yang merupakan pasar yang sangat potensial dan besar dengan penduduk lebih dari satu miliar. Menghadapi kebijakan tersebut, maka pada tahun 2012 Pemerintah Indonesia menetapkan Peraturan Menteri Perdagangan Republik Indonesia Nomor 21/M- Dag/Per/5/2010 Tahun 2010 tentang Penetapan Harga Patokan Ekspor atas Barang Ekspor yang dikenakan Bea Keluar dan pada tahun 2012 ekspor produk kakao dari Indonesia memiliki harga standar dalam ekspor kakao (Shandri, 2017).

\section{KESIMPULAN DAN REKOMENDASI KEBIJAKAN}

Berdasarkan hasil penelitian dapat disimpulkan bahwa nilai rata-rata RCA biji kakao Indonesia ke Malaysia dari tahun 1991 - 2017 adalah sebesar 22, artinya Indonesia memiliki keunggulan komparatif yang relatif tinggi. Namun, pada periode 2011 - 2017, nilai RCA cenderung menurun karena kurangnya pengolahan kakao di Indonesia sehingga komoditas yang diekspor hanya mengandalkan hasil primer berupa biji kakao. Nilai ekspor biji kakao sebagai bahan mentah menjadi faktor yang memengaruhi nilai ekspor yang rendah karena produk tidak diolah sehingga tidak memiliki nilai yang lebih tinggi daya saing ekspor biji kakao Indonesia di pasar internasional dengan negara tujuan Malaysia secara keseluruhan masih memiliki keunggulan komparatif karena biayanya yang rendah dibandingkan negara lain sehingga Indonesia mampu bersaing.

\section{DAFTAR PUSTAKA}

Arsyad, M., Sinaga, B., \& Yusuf, S. (2011). Analisis Dampak Kebijakan Pajak Ekspor dan Subsidi Harga Pupuk Terhadap Produksi dan Ekspor Kakao Indonesia Pasca Putaran Uruguay. Jurnal Sosial Ekonomi Pertanian, 8(1).

Badan Pusat Statistik. (2018). Badan Pusat Statistik. Retrieved from https://www.bps.go.id/subject/54/perkebunan.html

Direktorat Jenderal Perkebunan. (2015). Retrieved from http://ditjenbun.pertanian.go.id/tinymcpuk/gambar/file/statistik/2016 /Kakao \%202014-2016.pdf

Elfiana. 2014. Kebijakan Pajak Ekspor Terhadap Perkembangan Ekspor Kakao Di Indonesia. Lentera, 14(10).

Goenadi, DH., JB Baon, S Abdullah, Herman dan A. Purwoto. 2007. Prospek dan arah pengembangan agribisnis kakao. Edisi Kedua. Jakarta: Badan Litbang Pertanian. 
Lubis, A., \& Nuryanti, S. 2018. Analisis Dampak ACFTA dan Kebijakan Perdagangan Kakao di Pasar Domestik dan China. Retrieved from http:// ejurnal.litbang.pertanian.go.id/index.php/akp/article/view/419 $1 / 3534$

Shandri, D. 2017. Kebijakan Pemerintah Indonesia Menetapkan Harga Patokan Ekspor Produk Kakao Dari Indonesia ke Tiongkok Tahun 2012-2015. Jom Fisip, 4(2).

Syadullah, M. (2012). Dampak Kebijakan Bea Keluar Terhadap Ekspor Dan Industri Pengolahan Kakao. Litbang Perdagangan, 6(1).

Suryana, Anggita \& Fariyanti, Anna \& Rifin, Amzul. (2015). Daya Saing Kakao Indonesia di Pasar Internasional. Jurnal Manajemen dan Agribisnis. 